\title{
Aggressive crystalloid adversely affects outcomes in a pediatric trauma population
}

\author{
Hai Zhu ${ }^{1} \cdot$ Bailin Chen ${ }^{1,2} \cdot$ Chunbao Guo ${ }^{1,3,4}$ \\ Received: 25 November 2018 / Accepted: 3 April 2019 / Published online: 27 April 2019 \\ c) Springer-Verlag GmbH Germany, part of Springer Nature 2019
}

\begin{abstract}
Introduction Crystalloid resuscitation for trauma patients is deleterious, and minimizing crystalloid use is advocated. The purpose of this study was to evaluate the adverse effects of high-volume resuscitation in pediatric blunt trauma patients.

Methods This study included a retrospective review of 291 patients with blunt trauma from January 2007 to Apr 2018 at the Children's Hospital, Chongqing Medical University. Patients were dichotomized into low and high groups depending on the average dose of crystalloid fluid administration with a cut-off point during the first 24 or $48 \mathrm{~h}$. Propensity score matching was used based on measurable baseline factors to minimize confounding. The associations between crystalloid administration and clinical outcomes were determined according to the corresponding methods.

Results Patients who received larger doses of crystalloids were more likely than the low-volume group to be associated with severe anemia ( $p=0.033, p=0.042$, respectively), $\operatorname{RBC}$ transfusion $(p=0.016, p=0.009$, respectively) and longer hospital length of stay ( $p=0.008, p=0.002$, respectively). In terms of plasma transfusion and oral solid diet, there were marginally significant differences noted in the dichotomized groups at $24 \mathrm{~h}(p=0.074)$, with significant differences at $48 \mathrm{~h}(p=0.013)$. Conclusion Significant unfavorable outcomes were noted following excessive crystalloid resuscitation within the first $48 \mathrm{~h}$ among pediatric patients with blunt trauma. Our findings support the notion that excessive fluid resuscitation should be avoided.
\end{abstract}

Keywords Crystalloid administration $\cdot$ Length of hospital stay $\cdot$ Blunt trauma $\cdot$ Pediatric

\section{Introduction}

Chunbao Guo

guochunbao@cqmu.edu.cn; guochunbao@foxmail.com

Bailin Chen

785773319@qq.com

1 Department of Pediatric General Surgery and Liver Transplantation, Children's Hospital, Chongqing Medical University, 136 Zhongshan 2nd Rd., Chongqing 400014, People's Republic of China

2 Department of Neonatology, Children's Hospital, Chongqing Medical University, Chongqing 400014, People's Republic of China

3 Department of Pediatric General Surgery and Liver Transplantation, Children's Hospital of Chongqing Medical University, Ministry of Education Key Laboratory of Child Development and Disorders, Chongqing 400014, China

4 China International Science and Technology Cooperation Base of Child Development and Critical Disorders, Chongqing 400014, China
In the early stages of injury, trauma-induced hemorrhage is preventable; it represents a significant cause of death, accounting for $30-40 \%$ of trauma mortality in the pediatric population [1]. Traditionally, aggressive resuscitation strategies, the cornerstone of early trauma management, were advocated to increase the circulating volume and blood pressure to maintain end-organ perfusion $[2,3]$. It has been argued that this modality may be associated with deleterious clinical pathophysiological changes, including tissue edema, a hypocoagulable state in the pediatric population [4], burns [5], and also with the blunt trauma population [6]. Blood loss is increased with increased mean arterial pressure and dilution of clotting factors [7, 8]. Other adverse outcomes, including increased rates of postoperative ileus, acute respiratory distress syndrome (ARDS), abdominal compartment syndromes (ACS) and infectious complications including surgical site and blood stream infections were also reported with the use of high-volume crystalloid resuscitation [9]. 
After trauma, the optimal type of traditional fluid administration (crystalloid), quantity (large volumes) and timing of fluid administration have been questioned. It has been suggested that chloride-rich fluids [10] have detrimental effects on clinical outcomes in fluid resuscitation, likely due to the worsening of acidosis, local endothelial disruption and the volume overload it confers, triggering an inflammatory response that substantially increases morbidity [9]. Nevertheless, as signs of fluid responsiveness are not always easy to interpret, there has been a scarcity of clinical guidelines to direct this complex issue. A growing body of evidence points to substantial morbidity associated with even moderate volumes of resuscitative fluids. Nevertheless, it remains unclear as to whether commonly used resuscitative fluids, including both crystalloid or blood product therapies, are linked with adverse outcomes constituting a mere surrogate for injury severity or representing a truly causative effect [11-14].

As the exact volume of fluid resuscitation associated with worse outcome is unknown, we sought to evaluate the association of fluid accumulation with clinical outcomes in the pediatric trauma population at a large, tertiary care hospital, with the belief that restrictive crystalloid fluid therapy would be associated with better clinical outcomes.

\section{Methods}

This was a retrospective cohort study of the trauma inpatients during the ten-year period from January 2007 to Apr 2018 at our trauma center (Children's Hospital, Chongqing Medical University). The Ethics Committee of Chongqing Medical University gave expedited approval of this protocol. Inclusion criteria for this retrospective cohort study were as follows: all children below 16 years of age with blunt trauma; an injury severity score (ISS) of 9 or greater; blunt injuries to any body region except the brain; base deficit $2 \mathrm{mmol} / \mathrm{L}$ or higher; an abbreviated injury score (AIS) of 2 or more. Exclusion criteria were as follows: patients with missing data (gender, age, ISS, GCS, SBP, or intravenous [IV] fluid volume); operations performed in the first $48 \mathrm{~h}$; isolated traumatic brain injury; patients who were admitted to the study hospital later than $24 \mathrm{~h}$ after trauma; and those who received intravenous fluids before admission. To eliminate survivor bias, patients who arrived in extremis (no vital signs on presentation) and/ or died within $12 \mathrm{~h}$ of admission were also excluded from the analysis. The need for written informed consent was waived because all patients were treated according to routine institutional treatment guidelines. We currently do not have institutional guidelines for initial fluid resuscitation after trauma at our institution. Patient care for resuscitation and the decision to administer crystalloid, coagulation factor (CF) concentrates or blood product utilization was directed by the on-call attending trauma surgeon.

\section{Data collection}

Data regarding the type and timing of fluid and blood product administration, laboratory results, physiologic parameters and mortality outcomes were collected and thoroughly reviewed retrospectively from the patient medical records. We also reviewed patient demographics, type and injury severity scale (ISS), time elapsed between trauma and hospital admission, vital signs, arterial pressure, heart rate, blood cell count, hemoglobin, base excess (BE), hemorrhagic shock at admission, transfused blood components, and 24- or 48-h doses and the type of intravenous fluids administered. The abbreviated injury score (AIS) quantifies injuries from a score of 1 (minor injury) to 6 (nonsurvivable) in various body regions. A patient's ISS is calculated by summing the squares of the three highest AIS scores in three different body regions (values range from 1 to 75 ).

The primary outcomes of interest were blood components transfusion, ICU and hospital length of stay, ventilator days and 30-day mortality. The secondary outcomes were whether the patient developed the following complications: severe anemia (defined as nadir hemoglobin $7.0 \mathrm{~g} / \mathrm{dl}$ during hospital stay), thrombocytopenia (defined as nadir platelet count $50 \times 10^{9} / \mathrm{L}$ during hospital stay), acute renal failure (ARF), acute respiratory distress syndrome (ARDS), abdominal compartment syndrome (ACS), multiorgan failure (MOF), urinary tract infection (UTI) or blood stream infection.

\section{Propensity score (PS) matching and statistical analysis}

The study population was subdivided on the basis of average corrected crystalloid administrations in the first $24 \mathrm{~h}(80.15 \mathrm{~mL} / \mathrm{kg})$ and $48 \mathrm{~h}(150.15 \mathrm{~mL} / \mathrm{kg})$. The cohort was dichotomized into low- and high-crystalloid groups according to the average 24 or $48 \mathrm{~h}$ corrected crystalloid fluid administration as a cut-off point to ensure relative equality of group size. Because those receiving crystalloid therapy were not randomly assigned, propensity matching was performed using a 1:1 ratio nearest neighbor algorithm to minimize the effect of potential confounders in baseline characteristics. Propensity scores were estimated using a multivariable logistic regression model. A 0.1 caliper width was specified during the matching procedure and 
matching without replacement was performed based on the estimated propensity score of each patient. The selected covariates that were entered into the propensity model included age, gender, admission INR, admission hemoglobin, initial base deficit and ISS. These covariates were selected a priori based on the information that was available. Propensity model discrimination and goodness of fit were assessed for the balance of covariates used in propensity score estimation after matching using the C-statistic and the Hosmer-Lemeshow test, respectively. The propensity score analyses were performed using SPSS 20.0 (IBM, Armonk, NY) or R software 3.1.2 (The R Foundation for Statistical Computing) and the MatchIt package.

After PS matching, the matched low- and high-crystalloid administration patients were subjected to statistical comparisons using SPSS 20.0 (IBM, Armonk, NY). Continuous data are presented as the mean \pm standard deviation or median (minimum, maximum or 25 th and 75 th interquartile range (IQR), as indicated) unless otherwise indicated. Categorical data are reported as percentages. For univariate comparisons, Student's $t$-test, the Shapiro-Wilk test or Wilcoxon rank sum (Mann-Whitney $U$ test) were used to compare continuous variables, and $\chi 2$ tests or Fisher exact tests were used to compare categorical variables as appropriate. A $p$ value of 0.05 or less was considered significant with two-sided tests.

\section{Results}

During the 11-year study period (From January 2007 to Apr 2018), a total of 291 pediatric patients suffering from blunt injury and arriving at the study trauma center who were eligible for inclusion were entered into the final analysis (Table 1). Demographic data and trauma scores were available for all patients included in the study. The mean patient weight was $21.9 \mathrm{~kg}$, and $60.1 \%$ were male. The median injury severity score (ISS) was 24 . The average dose of crystalloid was $80.15 \mathrm{~mL} / \mathrm{kg}$ for the first $24 \mathrm{~h}$ and $127.26 \mathrm{~mL} / \mathrm{kg}$ for the first $48 \mathrm{~h}$ after adjusting for patient weight. Table 1 demonstrates the pattern of cumulative fluid balance between the two groups in the first 2 days. Overall, the daily fluid balance was more positive in the highcrystalloid group from the second day because fluid intake decreased in the low-crystalloid group.

The demographic and admission characteristics for the dichotomized groups based on respective average dose of crystalloid in the first $24 \mathrm{~h}$ or $48 \mathrm{~h}$ are presented in Tables 2 and 3. There were no significant differences with respect to age, gender, platelet count, hemorrhagic shock or Glasgow Coma Scale (GCS) score before PS-matching in the demographic features of patients between the two groups, with the exception of the median base deficit, ISS and initial hemoglobin upon admission. In terms of platelet count, marginally significant differences were noted in the dichotomized groups for $24 \mathrm{~h}$, but there were no significant differences for $48 \mathrm{~h}$ before PS-matching. Under PS-matching, several variables, including median admission base deficit, ISS and initial hemoglobin became comparable.

Table 4 demonstrates clinical outcomes for the dichotomized groups for $24 \mathrm{~h}$ and $48 \mathrm{~h}$. On univariate analysis, higher crystalloid volume was associated with more severe anemia ( $p=0.033, p=0.042$, respectively), more red blood cell (RBC) transfusion ( $p=0.016, p=0.009$, respectively) and longer hospital length of stay $(p=0.008, p=0.002$, respectively), than was the low-volume group. In terms of plasma transfusion and oral solid diet, there were marginally significant differences noted in the dichotomized groups for $24 \mathrm{~h}(p=0.074)$ but significant differences for $48 \mathrm{~h}(p=0.013)$.

In the entire cohort, 5 patients developed acute renal failure (ARF) (1.9\%), 3 patients developed ARDS (1.1\%), 1 patient developed abdominal compartment syndrome (0.4\%), no patients developed MOF, 10 had a UTI (3.8\%) and 8 developed a blood stream infection (3.0\%). Due to the exceedingly rare occurrence, the current data lacked statistical power to detect any association between crystalloid administration and ARF, ACS, ARDS, MOF, UTI or blood stream infections. Furthermore, patients in the high-volume group were more likely than their counterparts in the low-volume group to stay in the hospital longer (Table 4).

Table 1 Amount of crystalloid and fluids infused (mean \pm SD)

\begin{tabular}{|c|c|c|c|c|c|c|}
\hline \multirow[t]{2}{*}{ Mean $\pm \mathrm{SD}(\mathrm{ml} / \mathrm{kg})$} & \multicolumn{3}{|l|}{ Amount for $24 \mathrm{~h}$} & \multicolumn{3}{|l|}{ Amount for $48 \mathrm{~h}$} \\
\hline & $>80.15(\mathrm{~mL} / \mathrm{kg})$ & $<80.15(\mathrm{~mL} / \mathrm{kg})$ & $p$ & $>127.26(\mathrm{~mL} / \mathrm{kg})$ & $<127.26(\mathrm{~mL} / \mathrm{kg})$ & $p$ \\
\hline IV $0.9 \%$ saline & $67.5 \pm 11.3$ & $61.4 \pm 11.8$ & 0.000 & $105.5 \pm 18.5$ & $88.6 \pm 17.4$ & 0.003 \\
\hline IV crystalloids & $89.2 \pm 12.3$ & $71.3 \pm 13.4$ & 0.000 & $135.6 \pm 23.5$ & $119.6 \pm 22.3$ & 0.000 \\
\hline Water intake & $95.4 \pm 23.8$ & $84.6 \pm 22.9$ & 0.000 & $146.7 \pm 32.6$ & $129.6 \pm 30.3$ & 0.000 \\
\hline Urine output (mL/kg*h) & $59.3 \pm 15.8$ & $48.8 \pm 14.7$ & 0.006 & $113.3 \pm 26.9$ & $109.7 \pm 24.5$ & 0.12 \\
\hline Fluid balance & $26.6 \pm 8.7$ & $23.8 \pm 7.9$ & 0.058 & $47.2 \pm 13.6$ & $44.8 \pm 14.3$ & 0.089 \\
\hline
\end{tabular}

$I V$ intravenous injection; Mean $\pm S D$ mean \pm standard deviation 
Table 2 Baseline demographics of eligible patient and preoperative variables based on crystalloid administration in the first $24 \mathrm{~h}$

\begin{tabular}{|c|c|c|c|c|c|c|}
\hline & \multicolumn{3}{|l|}{ Total population } & \multicolumn{3}{|c|}{ Propensity matched population } \\
\hline & $<80.15(\mathrm{~mL} / \mathrm{kg})(145)$ & $>80.15(\mathrm{~mL} / \mathrm{kg})(146)$ & $p$ & $<80.15(\mathrm{~mL} / \mathrm{kg})(132)$ & $>80.15(\mathrm{~mL} / \mathrm{kg})(132)$ & $p$ \\
\hline Age (yrs), Mean \pm SD & $6.37 \pm 3.85$ & $6.56 \pm 3.79$ & 0.26 & $6.37 \pm 3.85$ & $6.56 \pm 3.79$ & 0.26 \\
\hline Male: female & $89: 56$ & $86: 60$ & 0.38 & $81: 51$ & $80: 52$ & 0.50 \\
\hline Weight $(\mathrm{kg})$, Mean \pm SD & $22.61 \pm 8.23$ & $20.54 \pm 7.61$ & 0.34 & $21.82 \pm 8.06$ & $21.34 \pm 7.92$ & 0.39 \\
\hline $\begin{array}{l}\text { Interval from injury }(\mathrm{h}) \\
\text { Mean } \pm \text { SD }\end{array}$ & $6.94 \pm 4.2$ & $6.76 \pm 4.4$ & 0.28 & $6.85 \pm 4.1$ & $6.81 \pm 4.2$ & 0.26 \\
\hline PT time (min), Mean \pm SD & $11.84 \pm 2.02$ & $12.48 \pm 1.88$ & 0.14 & $12.07 \pm 1.92$ & $12.35 \pm 1.67$ & 0.27 \\
\hline $\mathrm{APTT}(\min )$, Mean $\pm \mathrm{SD}$ & $32.87 \pm 6.48$ & $34.48 \pm 7.53$ & 0.19 & $33.28 \pm 7.53$ & $33.96 \pm 6.48$ & 0.36 \\
\hline INR (min), Mean \pm SD & $1.12 \pm 0.24$ & $1.18 \pm 0.27$ & 0.25 & $1.13 \pm 0.23$ & $1.15 \pm 0.26$ & 0.36 \\
\hline Fibrinogen $(\mathrm{g} / \mathrm{l})$, Mean \pm SD & $4.36 \pm 1.78$ & $4.05 \pm 2.16$ & 0.31 & $4.22 \pm 1.29$ & $4.17 \pm 1.87$ & 0.38 \\
\hline $\begin{array}{l}\text { Platelet count }\left(\times 10^{9} / 1\right) \\
\text { Mean } \pm \mathrm{SD}\end{array}$ & $168.64 \pm 76.83$ & $137.30 \pm 68.74$ & 0.075 & $153.46 \pm 68.64$ & $137.30 \pm 59.82$ & 0.22 \\
\hline Admission GCS, Mean \pm SD & $12.82 \pm 4.24$ & $13.67 \pm 3.92$ & 0.16 & $13.06 \pm 3.93$ & $13.18 \pm 3.62$ & 0.34 \\
\hline $\begin{array}{l}\text { Initial hemoglobin }(\mathrm{g} / \mathrm{dL}) \\
\text { Mean } \pm \mathrm{SD}\end{array}$ & $102.56 \pm 11.68$ & $88.64 \pm 10.45$ & 0.047 & $98.64 \pm 10.54$ & $92.58 \pm 10.16$ & 0.25 \\
\hline $\begin{array}{l}\text { Median admit base deficit } \\
(\mathrm{meq} / \mathrm{L}), \text { Mean } \pm \text { SD }\end{array}$ & $8.68 \pm 5.24$ & $10.14 \pm 6.27$ & 0.031 & $9.37 \pm 4.87$ & $9.86 \pm 5.78$ & 0.24 \\
\hline $\begin{array}{l}\text { Injury severity score (ISS), } \\
\text { median (IQR) }\end{array}$ & $17[9,47]$ & $28[9,49]$ & 0.000 & $21[9,42]$ & $24[10,44]$ & 0.19 \\
\hline $\begin{array}{l}\text { Hemorrhagic shock on admis- } \\
\text { sion, } n(\%)\end{array}$ & $24(16.6)$ & $28(19.2)$ & 0.33 & $22(16.7)$ & $25(18.9)$ & 0.32 \\
\hline
\end{tabular}

APTT Activated partial thromboplastin time; $P T$ prothrombin time; $G C S$ glasgow coma score; $I N R$ international normalized ratio; $M e a n \pm S D$ mean \pm standard deviation; $I Q R$ interquartile range

While the proportion of patients admitted to the ICU was significantly higher in the high-volume group, there were no significant differences in terms of mean ICU length of stay.

\section{Discussion}

Our data from a tertiary care hospital demonstrate that aggressive crystalloid resuscitation was associated with markedly more transfusion of RBC and significant delay of recovery measures, together with a longer hospitalization time among blunt injured children. We were not able to identify an association between crystalloid volume and other complications including ARDS, ACS, ARF or infectious complications due to their exceedingly rare occurrence, although this has been reported elsewhere [9]. This study should form an important step toward limited crystalloid administration for trauma practices worldwide.

During hemostatic resuscitation of massive hemorrhage, the role of crystalloid has been limited to that of carrier solution for blood products. It is plausible that the true impact of crystalloid administration on hemorrhage is variable, ranging from a protective effect, to no effect, to a detrimental effect, depending on the patient population, timing and volume of resuscitation. The inconsistency in findings of various investigators evaluating the association between crystalloid administration may partly be explained by variable risk adjustment [14]. Here, in the present study, we wanted to maintain power in our regression model ensuring inclusion of a number of relevant clinical characteristics, including injury severity, acute physiologic derangement, age and neurologic status that could be related to the risk of unfavorable outcomes, so that their effect would be controlled for in our analysis. Inadequate or inconsistent adjustment of these risks may result in spurious associations. We performed propensity score matching methods to control for the abovementioned comprehensive confounders to reduce the impact of indication bias. Compared to traditional multivariable models for risk adjustment, the current integration of propensity scores with traditional multivariable models offers a methodologic advantage in terms of reducing bias $[15,16]$. Interestingly, even after controlling for the aforementioned confounders, the incidence of unfavorable outcomes was significantly higher following higher volume crystalloid administration, likely suggesting a causative mechanism. Excess fluid administration might cause increased incidence of respiratory disorder due to fluid accumulation can inhibit gastrointestinal motility, so as to cause postoperative ileus $[17,18]$, the most important reason for increased length of stay. Actually, in the current setting, the oral solid diet was significantly delayed in the group that received larger crystalloid volumes. Furthermore, tissue 
Table 3 Baseline demographics of eligible patient and preoperative variables based on crystalloid administration in the first $48 \mathrm{~h}$

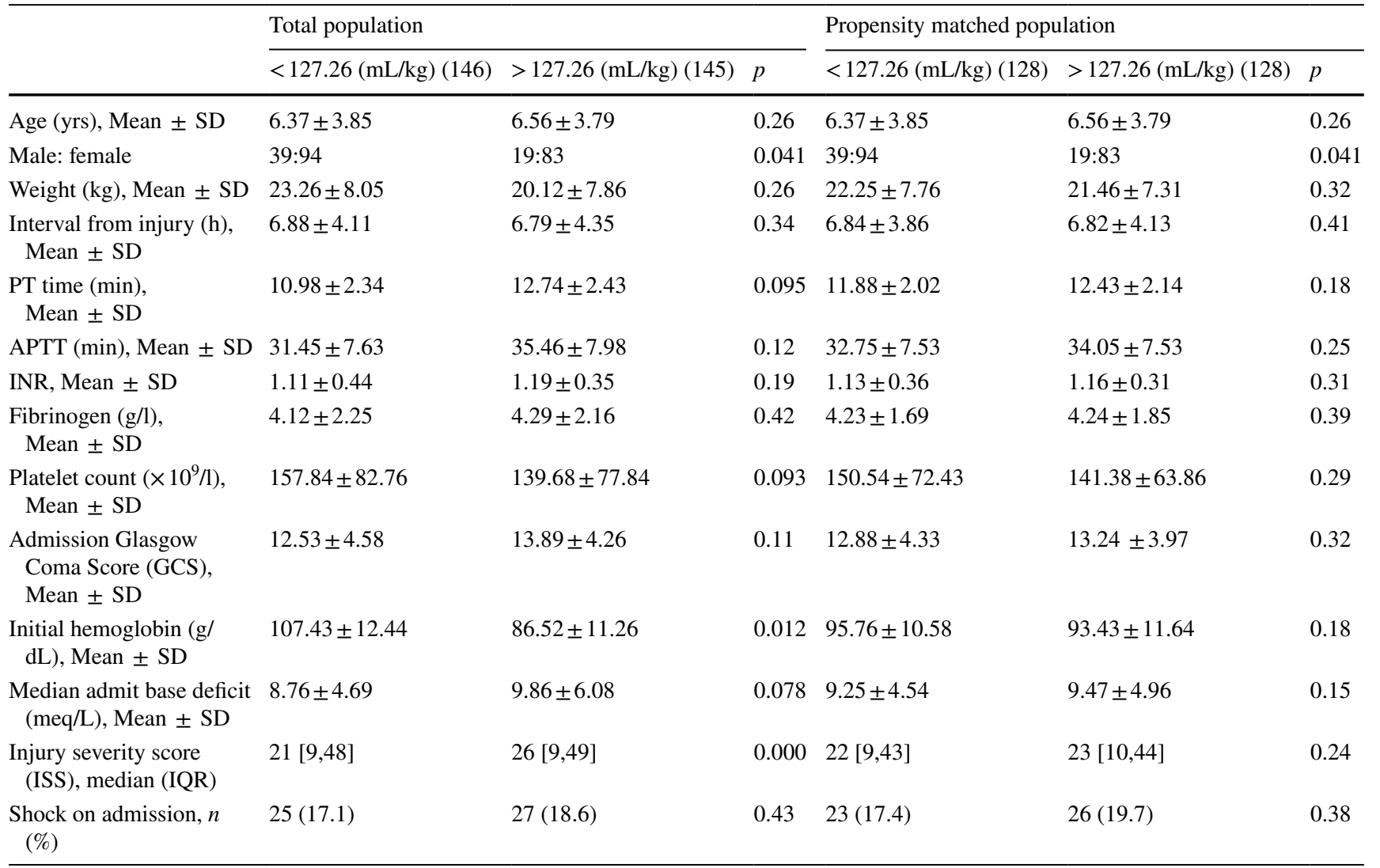

APTT activated partial thromboplastin time; PT prothrombin time; GCS glasgow coma score; INR international normalized ratio; Mean $\pm S D$ mean \pm standard deviation; $I Q R$ interquartile range

oxygenation might decline with fluid accumulation, a factor that is unfavorable for wound healing. Some data have indicated that sepsis and MOF correlated with increased fluid administration and blood transfusions, although this was not indicated in the current research.

A transient or negligible response to excess intravenous crystalloid, however, might increase intravascular pressure and unavoidably dilute coagulation factors, contributing to uncontrolled bleeding, necessitating the increase in transfusion of blood products $[19,20]$. One of the most intriguing findings in our study was the increased severe anemia and $\mathrm{RBC}$ transfusion in the larger crystalloid volume patients, even though the other blood product barely missed statistical significance in our adjusted analysis. The reduced hemodilution in the low volume of administration group may provide faster cessation of bleeding, possibly explaining the reduced RBC transfusion. Variation in the crystalloid administration window would be another factor accounting for the inconsistency of findings in other studies. To answer that question, by contrast with previously published efforts that have used 12-h and 24-h resuscitation volumes [9], we also elected to analyze resuscitation administered over the first $48 \mathrm{~h}$. We indeed identified fluid-related complications even according to the dose of crystalloid within $48 \mathrm{~h}$.

Taken together with previous guidelines and textbooks, the present data highlighted the benefits associated with restrictive fluid therapy in pediatric patients undergoing trauma resuscitation. As permissible strategies, low-volume resuscitation or hypotensive resuscitation has slowly but steadily grown in popularity to balance the risks of resuscitation with the goal of organ perfusion. While immediate and aggressive fluid resuscitation may rapidly improve vital signs, the overall effect on outcome may be much less comforting [21, 22]. Abnormal partial thromboplastin time, admission hemoglobin and base deficit were associated with greater risk for mortality than was systolic blood pressure [23, 24]. Because this strategy is still not widely used in the current pediatric surgical practices, evidence-based best practices should be performed to promote safer, higher quality patient care [25]. We believe this is a firm attempt at demonstrating the potential adverse outcomes that excessive fluid resuscitation may confer. As these complex interactions will continue to be in place, we urge the medical community with the privilege to care for the injured to refrain from this practice until well-designed 
Table 4 Patient outcomes according to the crystalloid fluids utilization following the PS matching

\begin{tabular}{|c|c|c|c|c|c|c|}
\hline & \multicolumn{3}{|c|}{$24 \mathrm{~h}$ crystalloid fluids utilization } & \multicolumn{3}{|c|}{$48 \mathrm{~h}$ crystalloid fluids utilization } \\
\hline & $<80.15(\mathrm{~mL} / \mathrm{kg})(132)$ & $>80.15(\mathrm{~mL} / \mathrm{kg})(132)$ & $p$ & $<127.26(\mathrm{~mL} / \mathrm{kg})(128)$ & $>127.26(\mathrm{~mL} / \mathrm{kg})(128)$ & $p$ \\
\hline $\begin{array}{l}\text { Acute renal failure (ARF), } \\
n(\%)\end{array}$ & $3(2.3 \%)$ & $2(1.5)$ & 0.50 & $3(2.3 \%)$ & $2(1.6 \%)$ & 0.50 \\
\hline $\begin{array}{l}\text { Oral solid diet (days), } \\
\text { Mean } \pm \text { SD }\end{array}$ & $3.2 \pm 1.1$ & $4.1 \pm 1.3$ & 0.074 & $3.1 \pm 1.0$ & $4.2 \pm 1.3$ & 0.013 \\
\hline $\begin{array}{l}\text { Urinary tract infection } \\
\text { (UTI), } n(\%)\end{array}$ & $6(4.5) \%$ & $4(3.0 \%)$ & 0.38 & $6(4.7 \%)$ & $3(2.3 \%)$ & 0.25 \\
\hline $\begin{array}{l}\text { Nadir Hb less than } 7 \mathrm{~g} / \mathrm{dl}, \\
n(\%)\end{array}$ & $6(15.9 \%)$ & $15(25.8 \%)$ & 0.033 & $5(14.1 \%)$ & $13(25.8 \%)$ & 0.042 \\
\hline $\begin{array}{l}\text { Nadir Plt less than } 50 \\
\left(\times 10^{9} / \mathrm{L}\right), n(\%)\end{array}$ & $2(6.8 \%)$ & $6(9.8 \%)$ & 0.14 & $2(7.0 \%)$ & $6(10.2 \%)$ & 0.14 \\
\hline \multicolumn{7}{|l|}{ Transfusion } \\
\hline $\begin{array}{l}\text { Total RBC (ml), median } \\
\text { (IQR) }\end{array}$ & $50(25-150)(n=27)$ & $100(25-200)(n=38)$ & 0.016 & $50(25-125)(n=25)$ & $100(25-175)(n=35)$ & 0.009 \\
\hline $\begin{array}{l}\text { Total Plasma (ml), median, } \\
\text { (IQR) }\end{array}$ & $50(25-150)(n=23)$ & $100(25-200)(n=35)$ & 0.093 & $50(25-125)(n=22)$ & $100(25-175)(n=33)$ & 0.032 \\
\hline $\begin{array}{l}\text { Total Platelets (U), median } \\
\text { (IQR) }\end{array}$ & $0(0-1)(n=1)$ & $1(0,2)(n=3)$ & 0.58 & $0(0-1)(n=1)$ & $1(0,2)(n=3)$ & 0.31 \\
\hline $\begin{array}{l}\text { Total cryoprecipitate (U), } \\
\text { median (IQR) }\end{array}$ & $0(0-0)(n=0)$ & $1(0,1)(n=2)$ & 0.31 & $0(0-0)(n=0)$ & $1(0,1)(n=2)$ & 0.38 \\
\hline ARDS, $n(\%)$ & $1(0.8 \%)$ & $2(1.5 \%)$ & 0.50 & $1(0.8 \%)$ & $2(1.6 \%)$ & 0.50 \\
\hline $\begin{array}{l}\text { Abdominal compartment } \\
\text { syndrome (ACS), } n(\%)\end{array}$ & $0(0 \%)$ & $1(0.8 \%)$ & - & 0 & $1(0.8 \%)$ & - \\
\hline $\begin{array}{l}\text { Multiorgan failure (MOF), } \\
n(\%)\end{array}$ & 0 & 0 & - & 0 & 0 & - \\
\hline $\begin{array}{l}\text { Blood stream infection, } n \\
(\%)\end{array}$ & $3(2.3 \%)$ & $5(3.8)$ & 0.12 & $3(2.3 \%)$ & $5(3.9 \%)$ & 0.36 \\
\hline $\begin{array}{l}\text { PICU Length of stay (d), } \\
\text { Mean } \pm \text { SD }\end{array}$ & $5(2-22)(n=13)$ & $5(2-22)(n=17)$ & 0.26 & $5(2-22)(n=12)$ & $5(2-22)(n=15)$ & 0.23 \\
\hline $\begin{array}{l}\text { Hospital Length of stay }(\mathrm{d}) \text {, } \\
\text { Mean } \pm \text { SD }\end{array}$ & $10.9 \pm 3.5$ & $12.7 \pm 4.2$ & 0.008 & $10.7 \pm 3.3$ & $12.8 \pm 4.0$ & 0.002 \\
\hline Mortality, $n(\%)$ & $1(0.8 \%)$ & $2(1.5 \%)$ & 0.50 & $1(0.8 \%)$ & $2(1.6 \%)$ & 0.50 \\
\hline $\begin{array}{l}\text { Ventilator days (d), median } \\
\text { (IQR) }\end{array}$ & $4(0-11)(n=11)$ & $6(0-19)(n=14)$ & 0.34 & $4(0-10)(n=11)$ & $6(0-17)(n=13)$ & 0.27 \\
\hline
\end{tabular}

Mean $\pm S D$ mean \pm standard deviation; $I Q R$ interquartile range; $P I C U$ pediatric intensive care unit; ARDS acute respiratory distress syndrome; $R B C$ red blood cell

randomized studies shed more light on the optimal method and goals of resuscitation. We hope to help develop optimal resuscitation strategies and protocols. In fact, at our institute, we implemented a fluid therapy strategy using tangible hemodynamic parameters to reduce hypo- and hypervolemia events.

The present study should be interpreted with certain limitations in mind. The current patient population might differ in their physiologic status during traumatic injury, because the ages of the pediatric patients ranged from 1 to 17 years. There are likely more subtle baseline differences among patients who could affect differences in treatment (i.e., balance of crystalloid vs. blood). Although we performed the PS-matching multivariate regression analysis, controlling for confounders is less rigorous in a retrospective analysis than in a randomized controlled trial. We did not consider adjusting for blood product utilization in our analysis. This information was considered as the outcome of fluid administration. A confounder is that the same adverse outcomes have also been associated with blood transfusion. Because there were only three deaths, no conclusions could be drawn about the influence of the resuscitative strategy on mortality. A more in depth stratification analysis for certain epidemiological data regarding the incidence, and mortality and morbidity rates should be performed to generate comparison groups of patients who had similar baseline factors should be next in my research agenda.

In summary, a high volume of crystalloid resuscitation fluid conferred prolonged hospital length of stay in a 
pediatric blunt trauma population. It also appeared to be associated with a substantial increase in severe anemia and RBC transfusion, even when baseline patient characteristics, trauma burden and blood product transfusions were controlled for. Our finding supports the notion that excessive fluid resuscitation should be avoided.

Acknowledgements We thank Prof. Xianqing Jin and Dr. Lei Li for providing technical assistance and for insightful discussions during the preparation of the manuscript. We thank Dr. Xiaoyong Zhang at the Wistar Institute, USA, for help with the linguistic revision of the manuscript.

Author contributions HZ, CG designed, analyzed the data and evaluated the manuscript. BC performed the statistical measurements and analyzed the data. CG analyzed the data and wrote the paper.

Funding The research was supported by National Natural Science Foundation of China (Nos: 30973440, 30770950), and the key project of the Chongqing Natural Science Foundation (CSTC, 2008BA0021, cstc2012jjA0155).

\section{Compliance with ethical standards}

Conflicts of interest No potential conflicts of interest relevant to this article are reported.

\section{References}

1. Kauvar DS, Lefering R, Wade CE. Impact of hemorrhage on trauma outcome: an overview of epidemiology, clinical presentations, and therapeutic considerations. J Trauma. 2006;60:S3-11.

2. Silva J, Gonçalves L, Sousa PP. Fluid therapy and shock: an integrative literature review. Br J Nurs. 2018;27:449-54.

3. Shires T, Coln D, Carrico J, Lightfoot S. Fluid therapy in hemorrhagic shock. Arch Surg. 1964;88:688-93.

4. Maitland K, Kiguli S, Opoka RO, Engoru C, Olupot-Olupot P, Akech SO, Nyeko R, Mtove G, Reyburn H, Lang T, Brent B, Evans JA, Tibenderana JK, Crawley J, Russell EC, Levin M, Babiker AG, Gibb DM, FEAST Trial Group. Mortality after fluid bolus in African children with severe infection. N Engl J Med. 2011;364:2483-95.

5. Klein MB, Hayden D, Elson C, Nathens AB, Gamelli RL, Gibran NS, Herndon DN, Arnoldo B, Silver G, Schoenfeld D, Tompkins RG. The association between fluid administration and outcome following major burn: a multicenter study. Ann Surg. 2007;245:622-8.

6. Holcomb JB, Jenkins D, Rhee P, Johannigman J, Mahoney P, Mehta S, Cox ED, Gehrke MJ, Beilman GJ, Schreiber M, Flaherty SF, Grathwohl KW, Spinella PC, Perkins JG, Beekley AC, McMullin NR, Park MS, Gonzalez EA, Wade CE, Dubick MA, Schwab CW, Moore FA, Champion HR, Hoyt DB, Hess JR. Damage control resuscitation: directly addressing the early coagulopathy of trauma. J Trauma. 2007;62:307-10.

7. McSwain NE, Champion HR, Fabian TC, Hoyt DB, Wade CE, Eastridge BJ, Proctor KG, Rasmussen TE, Roussel RR, Butler FK, Holcomb JB, Schreiber MA, Shackford SR, Blackbourne LH. State of the art of fluid resuscitation 2010: prehospital and immediate transition to the hospital. J Trauma. 2011;70:S2-10.

8. Bickell WH, Wall MJ Jr, Pepe PE, Martin RR, Ginger VF, Allen MK, Mattox KL. Immediate versus delayed fluid resuscitation for hypotensive patients with penetrating torso injuries. N Engl J Med. 1994;331:1105-9.

9. Kasotakis G, Sideris A, Yang Y, de Moya M, Alam H, King DR, Tompkins R, Velmahos G, Inflammation and Host Response to Injury Investigators. Aggressive early crystalloid resuscitation adversely affects outcomes in adult blunt trauma patients: an analysis of the Glue Grant database. J Trauma Acute Care Surg. 2013;74:1215-21.

10. Shaw AD, Bagshaw SM, Goldstein SL, Scherer LA, Duan M, Schermer CR, Kellum JA. Major complications, mortality, and resource utilization after open abdominal surgery: $0.9 \%$ saline compared to Plasma-Lyte. Ann Surg. 2012;255:821-9.

11. Inaba K, Branco BC, Rhee P, Blackbourne LH, Holcomb JB, Teixeira PG, Shulman I, Nelson J, Demetriades D. Impact of plasma transfusion in trauma patients who do not require massive transfusion. J Am Coll Surg. 2010;210:957-65.

12. Brakenridge SC, Phelan HA, Henley SS, Golden RM, Kashner TM, Eastman AE, Sperry JL, Harbrecht BG, Moore EE, Cuschieri J, Maier RV, Minei JP, Inflammation and the Host Response to Injury Investigators. Early blood product and crystalloid volume resuscitation: risk association with multiple organ dysfunction after severe blunt traumatic injury. J Trauma. 2011;71:299-305.

13. Duke MD, Guidry C, Guice J, Stuke L, Marr AB, Hunt JP, Meade $\mathrm{P}, \mathrm{McSwain}$ NE Jr, Duchesne JC. Restrictive fluid resuscitation in combination with damage control resuscitation: time for adaptation. J Trauma Acute Care Surg. 2012;73:674-8.

14. Garwe T, Johnson JJ, Letton RW. Indication bias explains some of the observed increased mortality associated with use of prehospital intravenous fluids in a pediatric trauma population. Acad Emerg Med. 2016;23:83-92.

15. Rubin DB. Estimating causal effects from large data sets using propensity scores. Ann Intern Med. 1997;127:757-63.

16. Neal MD, Hoffman MK, Cuschieri J, Minei JP, Maier RV, Harbrecht BG, Billiar TR, Peitzman AB, Moore EE, Cohen MJ, Sperry JL. Crystalloid to packed red blood cell transfusion ratio in the massively transfused patient: when a little goes a long way. J Trauma Acute Care Surg. 2012;72:892-8.

17. Grabitz SD, Farhan HN, Ruscic KJ, Timm FP, Shin CH, Thevathasan T, Staehr-Rye AK, Kurth T, Eikermann M. Dosedependent protective effect of inhalational anesthetics against postoperative respiratory complications: a prospective analysis of data on file from three hospitals in New England. Crit Care Med. 2017;45:e30-9.

18. O'Connor ME, Prowle JR. Fluid overload. Crit Care Clin. 2015;31(4):803-21.

19. Brown JB, Cohen MJ, Minei JP, Maier RV, West MA, Billiar TR, Peitzman AB, Moore EE, Cuschieri J, Sperry JL, Inflammation and the Host Response to Injury Investigators. Pretrauma center red blood cell transfusion is associated with reduced mortality and coagulopathy in severely injured patients with blunt trauma. Ann Surg. 2015;261:997-1005.

20. Brown JB, Sperry JL, Fombona A, Billiar TR, Peitzman AB, Guyette FX. Pre-trauma center red blood cell transfusion is associated with improved early outcomes in air medical trauma patients. J Am Coll Surg. 2015;220:797-808.

21. Pruitt BA Jr. Protection from excessive resuscitation: "pushing the pendulum back". J Trauma. 2000;49:567-8.

22. Balvers K, Wirtz MR, van Dieren S, Goslings JC, Juffermans NP. Risk factors for trauma-induced coagulopathy- and transfusion-associated multiple organ failure in severely injured trauma patients. Front Med (Lausanne). 2015;2:24.

23. Ley EJ, Clond MA, Srour MK, Barnajian M, Mirocha J, Margulies DR, Salim A. Emergency department crystalloid resuscitation of $1.5 \mathrm{~L}$ or more is associated with increased mortality in elderly and nonelderly trauma patients. J Trauma. 2011;70:398-400. 
24. MacLeod J, Lynn M, McKenney MG, Jeroukhimov I, Cohn SM. Predictors of mortality in trauma patients. Am Surg. 2004;70:805-10.

25. Krajewski ML, Raghunathan K, Paluszkiewicz SM, Schermer $\mathrm{CR}$, Shaw AD. Meta-analysis of high- versus low-chloride content in perioperative and critical care fluid resuscitation. Br J Surg. 2015;102:24-36. 